\title{
Improving Construction Procurement Systems using Organizational Strategies
}

\section{Heap-Yih Chong}

Faculty Engineering \& Science, Universiti Tunku Abdul Rahman, Setapak 53300, Kuala Lumpur, Malaysia

e-mail: chonghy@utar.edu.my

\section{Christopher N. Preece}

Razak School of Engineering \& Advanced Technology, Universiti Teknologi

Malaysia, 54100, Kuala Lumpur, Malaysia

e-mail: chrispreece@ic.utm.my

\begin{abstract}
Numerous types of construction procurement systems have been developed for project implementation. However, previous studies have not focused on subsequent managerial strategies and the project organizational forms to be adopted towards the selected procurement system. This research proposes that further managerial theories are required to enhance the project performance and effectiveness. Therefore, this paper aims to extract the principles of projectized and nonprojectized organizations and incorporate them with the selected procurement systems at the project level. A mechanism for assessing the key areas of compatibility was developed using the well established McKinsey $7 \mathrm{~S}$ model. The paper shows that the characteristics of the organizational principles are complementary with the procurement systems. It contributes an insight for future strategic organization and management at the project level in construction.
\end{abstract}

Keywords: projectized; nonprojectized; construction procurement systems; organizational principles; McKinsey; compatibility

\section{Introduction}

The construction industry is a highly fragmented sector due to the conventional practices [17] and supply chains [8]. This fragmentation inhibits the performance and effectiveness of construction projects. Well-coordinated organizational strategies are required to enhance communication and provide a clear understanding of the relationships and interdependencies among the stakeholders involved [4, 24, 35]. 
At the outset of construction projects, the managerial strategies include the selection of appropriate procurement systems or building-delivery methods to secure the success of the project $[6,7,9,21,28,29]$. In addition to traditional, design and build systems, innovative procurement systems have been developed such as improved private finance initiatives; public-private partnerships [13]; and specialist task organizations [36].

Today, many theories have been developed to address the emergence of increasingly complex organizational forms [18]. Yet, none has investigated on the selected procurement systems in terms of project management strategies and organizational forms. Hence, this paper aims to address this gap in knowledge by focusing on how project-based organizations, namely, projectized or nonprojectized organizations might be compatible with selected procurement systems for the successful implementation of projects. The review focuses on the micro level of project-based organizations, as opposed to the conventional approach, which is looking at the macro level of an entire organization [1]. The micro level incorporates the principles of project management strategy and organization into a single-project base. It was decided to focus on the lump-sum and design-and-build procurement systems for the purpose of this study.

It is believed that this review would add value to the existing project-management body of knowledge (PMBOK) in construction by examining how these construction-procurement systems could be implemented through projectized and nonprojectized organizations. The purpose of examining the compatibility of these management strategies and organizational approaches is to improve the process of marshalling the adequate human, material, and financial resources [44], as well as to enhance organizational performance and capabilities [15, 22, 43, 46]. Ultimately, it would provide a different perspective to the management organization of procurement systems in support of project effectiveness.

\section{Principles of Projectized and Nonprojectized Organizations}

Classical management principles consist of planning, organizing, staffing, controlling, and directing. At the macro or project level, organization is defined as a group of persons brought together for a purpose or to perform some type of work within an enterprise (Project Management Institute) [40]. Moreover, Kerzner (2006: 4) has defined project management as "the planning, organizing, directing, and controlling of company resources for a relatively short-term objective that has been established to complete specific goals and objectives". Each principle of project management has specific roles and activities to be performed at the micro level of a project, for instance, the organizational breakdown structure is a hierarchically organized depiction of the project's organization arranged so as to 
relate the work packages or a breakdown of the skill sets of the people who carry out the work in the various organizational units [40,44]. The management of a company needs to integrate from the business or company level, to the project level and to develop management strategies and a planned and systematic approach to project organization [2].

Projectized organization describes as any organizational structures in which the project manager has full authority to assign priorities, apply resources, and direct the work of persons assigned to the project [40].

The projectized organization can be further developed as a division within a division, whereby project managers maintain complete line authority over a continuous organizational flow of the project [24]. In other words, staffs report to only one person, which enables a strong communication channel within projects. Furthermore, team members are often collocated [40]. Learning and adoption of innovative solutions must be cultivated within the project's framework for developing its often highly customized outputs [2]. At the project level, the projects in projectized organizations are undertaken within a structure tailored to manage uncertainties or risks [10]. In addition, people require to undergo certain project-specific training and to possess specific competencies in project management.

The principles and theories of projectized organization are relatively new from a micro level perspective. A detailed empirical study needs to be carried out to identify the features of a projectized organization at the project level. Table 1 shows the implementation features that can be applied at the project level, obtained from literature review, which have been mainly modified from the advantages and disadvantages of projectized organization [24].

In the traditional approach, organization theories mainly classify the hierarchy structure for the upper levels of management. The features could be innovated and referred to at the project level. It would increase the project effectiveness and outcomes in terms of a proper coordination between the project manager and staff in the organizational structure.

On the contrary, the terminology of nonprojectized organization is rather new in organizational principles. Some describe it as a production-based [38] or functionfocused [16] organization. It a habitual management process for low-complexity and highly routinized work [10]. Nevertheless, the principles are related or derived from the classical functional organization, the management structure of which has survived for more than two centuries [24]. 
Table 1

Implementation features of projectized organization in project level

\begin{tabular}{|c|c|}
\hline Projectized Organization in General [24] & $\begin{array}{l}\text { Projectized Organization in Project } \\
\text { Level }\end{array}$ \\
\hline $\begin{array}{l}\text { Advantages } \\
\text { - } \quad \text { Provides complete line authority over project } \\
\text { - } \quad \text { Participants work directly for the project manager. Unprofitable product lines are easily } \\
\text { - } \quad \text { Strontified and can be eliminated } \\
\text { - Staffs can maintain expertise on a given project without sharing key personnel } \\
\text { - } \quad \text { Vary rapid reaction time is provided } \\
\text { - } \quad \text { Personnel demonstrate loyalty to the project; better morale with product identification } \\
\text { - } \quad \text { flexibility in determining time, cost and performance trade-offs } \\
\text { - Interface management becomes easier as unit size is decreased } \\
\text { - Upper-level management maintains more free time for executive decision-making }\end{array}$ & \multirow{2}{*}{$\begin{array}{l}\text { Implementation Features } \\
\text { - } \quad \text { Full authority in a maximized } \\
\text { communication structure for } \\
\text { Project manager } \\
\text { - } \quad \text { Direct control to participants } \\
\text { and project lines } \\
\text { - } \text { Quick response as easy interface } \\
\text { management } \\
\text { - } \quad \text { High loyalty and morale for } \\
\text { personnel } \\
\text { Flexibility but lack of } \\
\text { interchange opportunities } \\
\text { between projects } \\
\text { - Higher cost } \\
\text { Poor transferring of knowledge } \\
\text { management or perpetuation of } \\
\text { technology }\end{array}$} \\
\hline $\begin{array}{l}\text { Disadvantages } \\
\text { - Cost of maintaining this form in a multiproduct company would be prohibitive due to } \\
\text { - } \quad \text { Auplication of effort, facilities, and personnel; inefficient usage } \\
\text { management must balance workloads as projects start up and are phased out } \\
\text { - Technology suffers because, without strong functional groups, outlook of the future to improve } \\
\text { compnay's capabilities for new programs would be hampered (i.e., no perpetuation of } \\
\text { - } \quad \text { Cechnology) } \\
\text { - Lack of opportunities for technical interchange between projects } \\
\text { - Lack of career continuity and opportunities for project personnel }\end{array}$ & \\
\hline
\end{tabular}


The nonprojectized organization produces identical or similar projects with minimal uncertainties and variations [38]. People working on such projects do not really require substantial project-management knowledge and this type of organization consumes human and material resources much above normal operations [10]. Before the implementation features of nonprojectized organization can be identified, the advantages and disadvantages of a classical organization need to be reviewed. Table 2 lists the advantages and disadvantages of a classical or functional organization.

Table 2

Advantages and disadvantages of classical organization (Kerzner, 2006)

\begin{tabular}{|c|c|}
\hline Advantages & Disadvantages \\
\hline 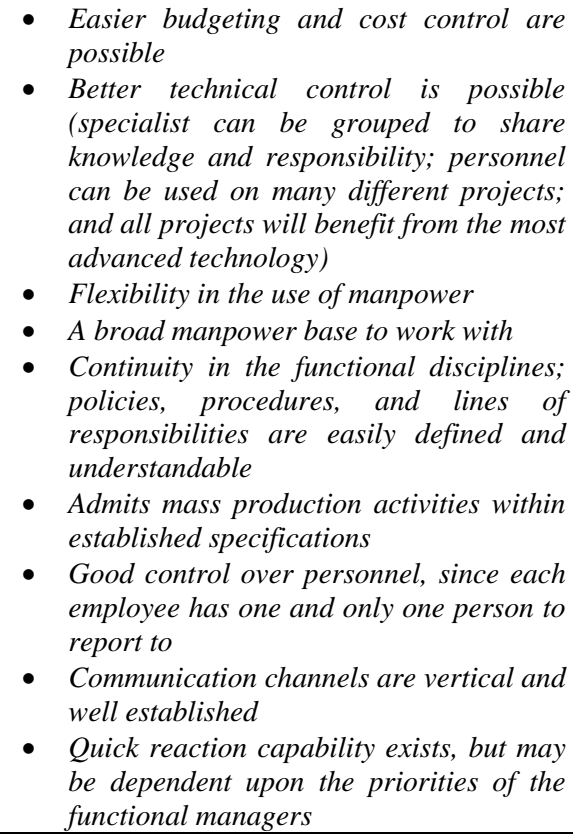 & 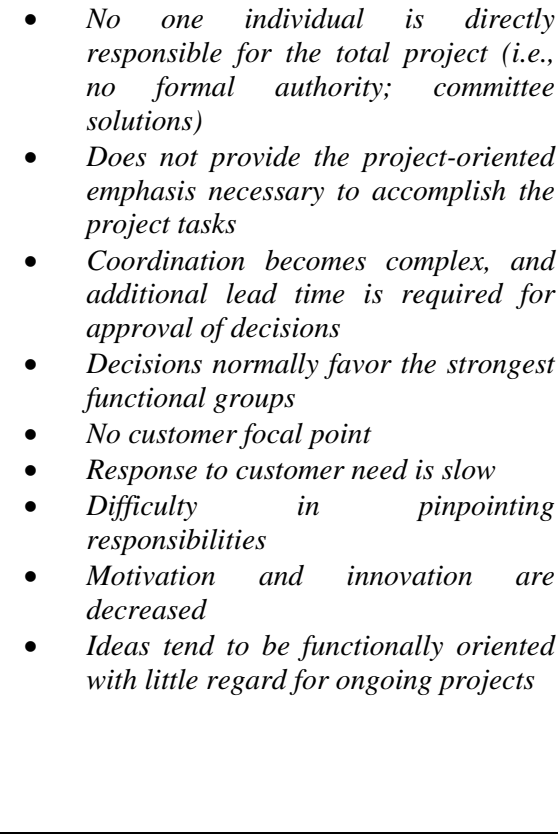 \\
\hline
\end{tabular}

At the project level, the structure of a nonprojectized organization divides individually among all departments or functions within the project. The implementation features below are innovated or derived from literature review for the project level such as:

- Better control within a department or function of the project

- $\quad$ Variety of specialists can be hired

- $\quad$ Policies and responsibilities are clearly defined for each department

- $\quad$ Minimal risks and variations 
- $\quad$ Communication channels are vertical or through upper-level management

- $\quad$ People require less project-management knowledge

- $\quad$ Lack of coordination and poor decision-making process

In summary, the implementation features of projectized or nonprojectized organizations were identified and could be applied at the project level. A successful implementation of organizational factors would improve the project performance [34]. It considers the authorities, responsibilities, and lines of control when organizing and integrating people into an effective work team. As a result, a well-organized work team would facilitate clear communication and management approaches.

\section{Procurement Systems}

Recent developments in procurement systems have focused on electronic-based procedures[14, 25, 26]. Theories of information systems have widely applied in procurement systems to simplify and enhance the process of procurement as well as legal aspects of a business [33]. Therefore, certain management strategies could be incorporated into procurement systems. This is a complementary and value added approach to the current developments in e-procurement systems.

Generally, a procurement system is a managerial structure that adopted by the client for the implementation, and at times eventual operation of a project [32]. The management of project procurement requires the contract management and change control to efficiently administer projects [40]. Project-delivery methods are related to the contract strategies used for the acquisition of goods or services involving the employer and the contractor.

Besides, lump-sum procurement system also describes as a fixed-price contract, which is the most common type of contract in the construction industry. This type of system always associates with the traditional approach to contracts, wherein competitive tendering and a bill of quantities commonly use in the project [42]. The contractor obliges to carry out the work at the negotiated contract value, and this type would provide the maximum cost protection for the employer if zero or minimal variations occur during the project [24]. The construction industry is full of risks and uncertainties. Procurement systems deal with risk allocation between the contractor and the employer. In a lump-sum contract, the risk allocation is regarded as fairer and more balanced in the perspective of employers because the employer has a better control in terms of the performance of the contractor and change management along the project. The roles and responsibilities are well defined and differentiated for the professionals who work in the project under this procurement system, particularly for the design-and-construction processes. 
On the contrary, the design-and-build system overcomes the problem of having separate design and construction processes by incorporating them into a single organization [3]. This system requires the contractor to design and construct the project in a single contract package. It places the responsibility of saving the construction time and costs solely on the contractor. Usually, a design-and-build project is often associated with a negotiated approach of contract due to tight time requirements [20]. A competent contractor is selected through negotiations from among several short-listed contractors. Moreover, the design and construction can be carried out concurrently to shorten the project duration. One of primary reasons on why employers select the design-build procurement system is to shorten the overall project duration [11]. This ensures smooth cash flow and financial stability [23]. There are several pros and cons in relation to these two procurement systems. In general, the advantages and disadvantages of these methods could be summarized, as shown in Table 3 [42].

Table 3

Advantages and disadvantages of lump sum (traditional approach) and design and build systems [42]

\begin{tabular}{|c|c|}
\hline Advantages & Disadvantages \\
\hline \multicolumn{2}{|l|}{ Traditional approach: } \\
\hline Competitive tendering is used & Decision process are slow and convoluted \\
\hline $\begin{array}{l}\text { Bill of quantities make for case of valuation } \\
\text { of variations }\end{array}$ & $\begin{array}{l}\text { Total project time is the longest of all } \\
\text { options }\end{array}$ \\
\hline $\begin{array}{l}\text { High quality and functional standards are } \\
\text { possible }\end{array}$ & It has low levels of buildability \\
\hline $\begin{array}{l}\text { There is cost certainty at the start of } \\
\text { construction }\end{array}$ & $\begin{array}{l}\text { Many organizational interfaces must be } \\
\text { managed }\end{array}$ \\
\hline $\begin{array}{l}\text { Independent advice is given on most } \\
\text { aspects of the process }\end{array}$ & \\
\hline \multicolumn{2}{|l|}{ There are clear line of accountability } \\
\hline \multicolumn{2}{|l|}{$\begin{array}{l}\text { A combination of best design and } \\
\text { construction skills is possible }\end{array}$} \\
\hline \multicolumn{2}{|l|}{ There is flexibility for design changes } \\
\hline \multicolumn{2}{|l|}{ Design and build } \\
\hline There is single point of responsibility & There is very lack independent advice \\
\hline Fixed price bids are used & $\begin{array}{l}\text { Valuation of variations is not based on fixed } \\
\text { price }\end{array}$ \\
\hline Design and construction are integrated & $\begin{array}{l}\text { It requires a detailed brief and client } \\
\text { requirements at the outset }\end{array}$ \\
\hline It has high levels of buildability & Changes can be expensive \\
\hline Total project times are short & $\begin{array}{l}\text { Client control of quality and functionality is } \\
\text { minimized }\end{array}$ \\
\hline $\begin{array}{l}\text { Client involvement in the process can be } \\
\text { minimized }\end{array}$ & $\begin{array}{l}\text { Design and build firms lack of broad } \\
\text { experience or expertise }\end{array}$ \\
\hline $\begin{array}{l}\text { Package deal systems offer off-the-shelf } \\
\text { solutions }\end{array}$ & $\begin{array}{l}\text { There are lower level of competition at } \\
\text { tender than in the other approaches }\end{array}$ \\
\hline There is competition on price and product & $\begin{array}{l}\text { The tender process can be expensive to } \\
\text { bidders }\end{array}$ \\
\hline & $\begin{array}{l}\text { Comparison of bids can be complicated } \\
\text { It may not produce well-thought-out bids }\end{array}$ \\
\hline
\end{tabular}


Overall, procurement systems merely allocate risks and responsibilities between the prime contracting parties within a project. They focus on contract management. Therefore, it is important to look at other perspectives of managerial approach to enhance the effectiveness of procurement systems, particularly, the incorporation of suitable principles of projectized or nonprojectized organizations into procurement systems.

\section{Development of A Mechanism for Analyzing the Compatibility of Different Procurement Systems and Organizational Forms}

The McKinsey Seven S model was developed in the early 1980's by McKinsey and Company [37, 39]. This well-established framework explains and analyses both "hard" and "soft" aspects of organisational management such as strategy, structure, systems, shared values, style, staff, and skills. It is also closely related and applicable to a project delivery approach as the model is recognized for its completeness and comprehensiveness.

The shape of the model explains the interdependency of the variables as illustrated in Figure 1. The variables consider to be of critical importance to managers and practitioners [39].

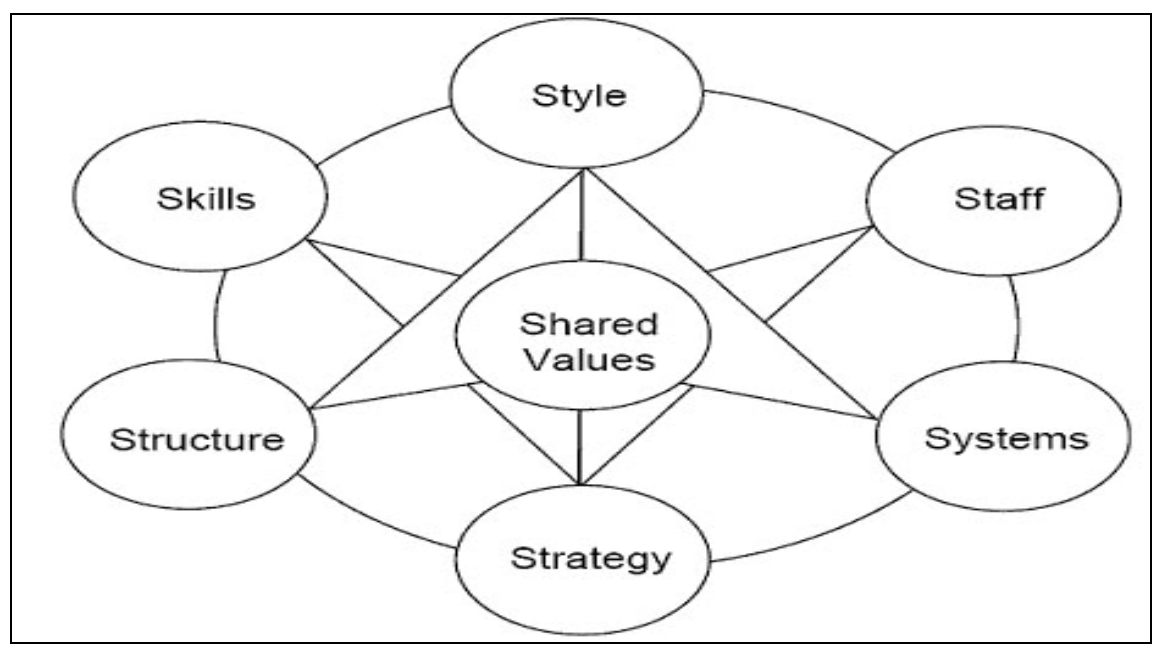

Figure 1

McKinsey Seven S Model [39] 
Therefore, the Seven S "levers" was adopted in this review to organise the criteria of organizational management in order to assess the compatibility of the organisational forms (nonprojectized and projectized) with the selected procurement systems. They seem to be broad enough to encompass the critical aspects of implementing organisational management at the level of the project. In addition, they provide an important link to the business level of construction organisations where corporate and commercial strategic decisions are taken into consideration. As a result, it creates a significant impact on project level strategies and organisation. The details of the Seven S Model and its expansion and explanation for the construction project are as follow:

- Strategy describes as a plan or course of action in allocating resources to achieve identified goals over time [5, 45]. To the procurement systems as mentioned, they relate to the constraints for their design performance and requirements as well as overall project control.

- Structure defines as a skeleton of the organisation or the organisational chart [5, 45]. However, in construction project level, it is about the overall project delivery mechanism, particularly for organising the tasks involved and its layers of management.

- Systems are the routine processes and procedures followed within the organisation [30]. It is similar for the scope of works and job activities at the project level.

- Shared values refer to the significant meanings or guiding concepts that organisational members share [31, 39]. The culture of the overall management would determine the shared values (outcomes) generated from the other $6 \mathrm{~S}$ at the project level.

- The way in which key managers behave in achieving organisational goals is considered to be the style variable; this variable is thought to encompass the cultural style of the organisation. In the construction project level, it is about the project leadership towards the authorities and communication among the workers or management teams.

- Staff describes as personnel categories within the organisation (e.g. engineers), whereas the skills variable refers to the capabilities of the staff within the organisation as a whole [41]. This relates to the level of capabilities required for the workforce at the project level.

- Skills refer to the actual level of skills and competencies of the employees working for the company. In the construction context, it is about the degree of specialization required for the project delivery approach.

Subsequently, the McKinsey $7 \mathrm{~S}$ model has been reviewed for checking the degree of compatibility for the strategic management organization and the procurement systems at the level of the construction project as shown in Table 4. 
Table 4

Compatibility assessment for selected procurement systems and organisational forms utilising McKinsey Seven S Model

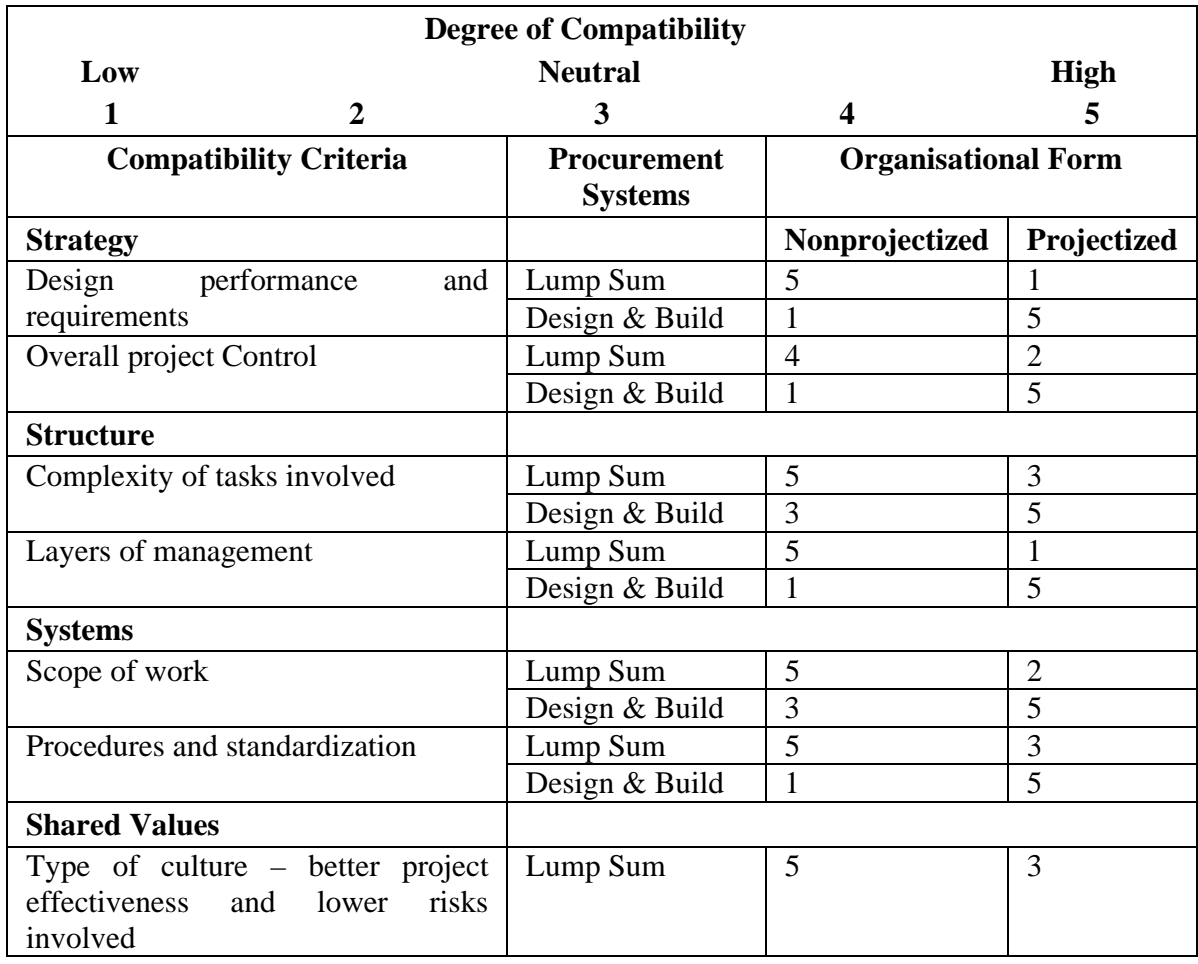

The comparison refers to general practice under a common scenario. According to the literature, the lump sum procurement system has a high compatibility level with the nonprojectized organization for all the 7S except for Skills. It is because a relatively high degree specialization is required for the procurement system compared to the nonprojectized organization in most cases, for example, a high rise and sophisticated building. Yet, the nonprojectized organization is quite relevant to the lump sum procurement system on less-complicated projects, which both promote a low degree of specialization for the routinized works.

On the other hand, the design and build system has a very high compatibility level with the projectized organization for all the $7 \mathrm{~S}$. Both have a similar principle and approach in project delivery based on the review of the literature. However, the criteria of Structure, System, Staff and Skills were rated as neutral for the design and build with the nonprojectized organization. It is because these areas are subjected to further invesitgation on the actual project requirements and conditions. Overall, the cross comparison has distinguished a preliminary assessment of level of compatibility for the procurements systems and the organization principles. 


\section{Integration and Discussion}

The existing procurement systems have served well within a project in terms of contractual arrangements and risk allocations [12, 27, 42]. However, procurement systems could be further improved, particularly at the perspective of its organizational form in order to have a more collaborative planning and organization at the outset of a project [19]. The organizational principles focus on the micro or project level. Different perspectives of organizational principles could be used to enhance the organizational approach to a project in the context of management.

In the context of construction management, project managers usually tend to select an appropriate procurement system for managing the project. It is very rare to have a well-organized form of organization for a particular contract arrangement in a project. Therefore, the integration herein aims to incorporate the organizational principles such that they work well in conjunction with procurement systems.

According to the review, the principles of projectized organization deem appropriate for design-and-build procurement systems. The features of a projectized organization are aligned with the design-and-build principles, where responsibilities of the contractor in terms of design and construction require a complete and unambiguous line of authority and communication structure within the project. When the project manager has a direct control over and response from the project participants, he or she could control or manage the project more effectively in the projectized organizational form. Moreover, these two methods also share the same shortcomings in terms of their principles, in which the designand-build projects are costly and their technologies or constructions are typically sophisticated or completed on a one-time basis and are hardly flexible enough to be transferred to other projects.

Besides, the principles of nonprojectized organizations are well integrated with the lump-sum procurement system. The distinct departments and processes of the organizational form are able to streamline the project's effectiveness for the lumpsum contract when different specialists control their departments and perform their duties individually with a clear policy. This environment could produce a better product at a lower cost, where the risks or uncertainties are minimal and handled properly within each department. Nevertheless, the project requires long duration in this combination.

Apart from that, certain limitations of this empirical study need to be considered. The integration was carried out based on literature reviews by examining the fundamental characteristics of the projectized and nonprojectized organizational forms in a systematically approach, which highlighted each similarity and difference in terms of the compatibility for their principles. It has detailed the preliminary development and application of a mechanism for analyzing the 
compatibility of construction procurement systems and organizational management forms. It has attempted to use the well established McKinsey $7 \mathrm{~S}$ model from general strategic management and applied it at the level of the construction project. Nevertheless, more works are required in developing the criteria under each of the interrelated $7 \mathrm{~S}$ to see whether the mechanism might be used as a generic tool for assessing compatibility.

The results would be more convincing if the integration could be tested and applied to real construction projects in the future. Meanwhile, It also could consider and promote integral management for the governance and management of enterprises [47, 48]. In addition, the study should extend to other organizational management strategies and forms and procurement systems, such as hybrid or matrix organization structures, cost-reimbursement systems, guaranteed maximum systems, and so on. These two limitations serve as the topics for future research.

\section{Conclusion}

Conventionally, procurement systems mreley focus on risk allocation and contract management. This paper highlights an innovative approach of incorporating the principles of projectized and nonprojectized organizations to selected procurement systems, namely, lump-sum and design-and-build systems. McKinsey $7 \mathrm{~S}$ model was adopted as a basic mechanism in reviewing the significant aspects of strategic management organization at the level of the construction project. It has identifed the key areas of compatibility between procurement systems and organizational forms.

The combined values were generated based on a comprehensive literature analysis. It provides a useful reference in construction project management. In summary, procurement systems can become more organized and effective by applying the organizational management strategies and structural forms of (a) design-and-build systems in conjunction with principles of projectized organizations, and (b) lump-sum systems in association with principles of nonprojectized organizations. The theory of incorporation renders an important insight for further enhancement of PMBOK from the viewpoints of both procurement systems and project organization theories.

\section{References}

[1] Alvarez, S. A., Paker, S. C. Emerging Firms and the Allocation of Control Rights: A Bayesian Approach. Academy of Management Review, 34, 209227, 2009

[2] Arenius, M., Artto, K. A., Lahti, M., Meklin, J. Project Companies and the Multi-Project Paradigm: a New Management Approach. In: Slevine DP, Cleland DI, Pinto JK. (Eds.). The Frontiers of Project Management Research. Newtown Square: Project Management Institute, 2002

[3] Ashworth, A. Contractual Procedures in the Construction Industry. London: Pearson, 2006 
[4] Benedek, P Compliance Management - A New Response to Legal and Business Challenges. Acta Polytechnica Hungarica, 9 (3), 135-148, 2012

[5] Boyle, S. Impact of Changes in Organisational Structure on Selected Key Performance Indicators for Cultural Organisations. International Journal of Cultural Policy, 13, 319-334, 2007

[6] Chan, A. P. C., Yung, E. H. K., Lam, P. T. I., Tam, C. M., Cheung, S. O. Application of Delphi Method in Selection of Procurement Systems for Construction Projects. Journal of Construction Management and Economics, 19, 699-718, 2001

[7] Chan, A. P. C. Evaluation of Enhanced Design and Build System: a Case Study of a Hospital Project. Journal of Construction Management and Economics, 18, 863-871, 2000

[8] Cheng, J. C. P., Law, K. H., Bjornsson, H., Jones, A., Sriram, R. A Serviceoriented Framework for Construction Supply Chain Integration. Automation in Construction, 19, 245-260, 2010

[9] Cheung, S. O., Lam, T-I., Wan, Y-W. Lam, K-C. Improving Objectivity in Procurement Selection. Journal of Management in Engineering, 17, 132139, 200

[10] Chiocchio, F., Beaulieu, G., Boudrias, J-S., Rousseau, V., Aube, C., Morin, E. M. The Project Involvement Index, Psychological Distress, and Psychological Well-Being: Comparing Workers from Projectized and Nonprojectized Organizations. International Journal of Project Management, 28, 201-211, 2010

[11] Cho, K. M., Hyun, C. T., Koo, K. J., Hong, T. H. Partnering Process Model for Public-Sector Fast-Track Design-Build Projects in Korea. Journal of Management in Engineering, 26, 19-29, 2010

[12] Chong, H-Y., Zin, R. M. A Case Study into the Language Structure of Construction Standard form in Malaysia. International Journal of Project Management, 28:601-608, 2010

[13] Clifton, C., Duffield, C. F. Improved PFI/PPP Service Outcomes through the Integration of Alliance Principles. International Journal of Project Management, 24, 573-586, 2006

[14] Elbanna, A. From Intention to Use to Actual Rejection: The Journey of an e-procurement System. Journal of Enterprise Information Management, 23, 81-99, 2010

[15] Fortune, A, Mitchell, W. Unpacking Firm Exit at the Firm and Industry Levels: The Adaptation and Selection of Firm Capabilities. Strategic Management Journal, 33, 794-819, 2012 
[16] Frigenti, E., \& Comninos, D. The Practice of Project Management - A Guide to the Business-focused Approach. London: The Bath Press Ltd, 2002

[17] Gluch, P. Unfolding Roles and Identities of Professionals in Construction Projects: Exploring the Informality of Practices. Journal of Construction Management and Economics, 27, 959-968, 2009

[18] Gulati, R, Puranam, P., Tushman, M. Meta-Organization Design: Rethinking Design in Interorganizational and Community Contexts. Strategic Management Journal, 33, 571-586, 2012

[19] Gunter, H., Grote, G. Collaborative Planning and its Antecedents: An Assessment in Supply Chain Relationships. Journal of Management and Organization, 18, 36-52, 2012

[20] Halpin, D. W. Construction Management. New York: John Wiley \& Sons, 2006

[21] Ive, G., Chang, C-Y. The Principle of Inconsistent Trinity in the Selection of Procurement Systems. Journal of Construction Management and Economics, 25, 677-690, 2007

[22] Jost, P-J., Lammers, F. The organization of Project Evaluation under Competition. Review of Managerial Science, 3, 141-155, 2009

[23] Kaplanoglu, S. B., Arditi, D. Guidelines for Pre-Project Peer Reviews in Construction Contracting. International Journal of Project Organisation and Management, 2, 154-173, 2010

[24] Kerzner, H. Project Management: A Systems Approach to Planning, Scheduling and Controlling. New Jersey: John Willey \& Sons, 2006

[25] Ketikidis, P. H., Kontogeorgis, A., Stalidis, G., Kaggelides, K. Applying eprocurement System in the Healthcare: The EPOS paradigm. International Journal of Systems Science, 41, 281-299, 2010

[26] Liu, Q., Sun, S. X., Wang, H., Zhao, J. A Multi-Agent-based System for eprocurement Exception Management. Knowledge-Based Systems, 24, 4957, 2011

[27] Lumineau, F., Quélin, B. V. An Empirical Investigation of Interorganizational Opportunism and Contracting Mechanisms. Strategic Organization, 10, 55-84, 2012

[28] Luu, D. T., Ng, S. T., Chen, S. E., Jefferies, M. A Strategy for Evaluating a Fuzzy Case-based Construction Procurement Selection System. Advances in Engineering Software, 37, 159-171, 2006

[29] Luu, D. T., Ng, S. T., Chen, S. E. Parameters Governing the Selection of Procurement System - An Empirical Survey. Engineering, Construction and Architectural Management,10, 209-218, 2003 
[30] Lynch, R. Corporate Strategy, $4^{\text {th }}$ edition. Prentice Hall: UK, 2005

[31] Martins, E., Terblanche, F. Building Organisational Culture that Stimulates Creativity and Innovation. European Journal of Innovation Management, 6, 64-74, 2003

[32] Masterman, J. W. E. An Introduction to Building Procurement Systems. Spon Press: New York, 2002

[33] Mishra, A., Mishra, D A Legal Business Information System: Implementation Process Context. Acta Polytechnica Hungarica , 8 (2), 4559, 2011

[34] Mollick, E. People and Process, Suits and Innovators: The Role of Individuals in Firm Performance. Strategic Management Journal, 33, 10011015, 2012

[35] Mueller, J. The Interactive Relationship of Corporate Culture and Knowledge Management: A Review. Review of Managerial Science, 6, 183-201, 2012

[36] Oyegoke, A. S., Kiiras, J. Development and Application of the Specialist Task Organization Procurement Approach. Journal of Management in Engineering, 25, 131-142, 2009

[37] Pascale, R., Athos, A. The Art of Japanese Management. Penguin Books: London, 1981

[38] Patrick, F. Multi-Project Constraint Management: the "Critical Chain" Approach. In: Dinsmore PC, Cabanis-Brewin J. (Eds.), The AMA Handbook of Project Management. Amacom American ManagementL: New York, 2006

[39] Peters, T., Waterman, R. In Search of Excellence. Harper \& Row: New York, 1982

[40] PMI (2008) A Guide to the Project Management Body of Knowledge, Project Management Institute: Pennsylvania, 2008

[41] Purcell, J., Boxal, P. Strategy and Human Resource Management (Management, Work and Organisations. Palgrave Macmillan: UK, 2003

[42] Rowlinson, S. M., McDermott, P. Procurement Systems: A Guide to Best Practice in Construction. E \& FN Spon: London, 1999

[43] Scherpereel, C. M. The Option-Creating Institution: A Real Options Perspective on Economic Organization. Strategic Management Journal, 29, 455-470, 2008

[44] Turner, J. R. The Handbook of Project Based Management. MrGraw-Hill: New York, 2009 
[45] Waterman, R. Jr., Peters, T., Phillips, JR. Structure Is Not Organisation. Business Horizons, 23,14-26, 1980

[46] Yoo, J. W., Kim, K. Board Competence and the Top Management Team's External Ties for Performance. Journal of Management and Organization, 18, 142-158, 2012

[47] Belak, J., Duh, M. Integral Management: Key Success Factors in the MER Model. Acta Polytechnica Hungarica, 9, 5-26, 2012

[48] Belak, J., Milfelner, B. Enterprise Culture as One of the Enterprise's Key Success Factors (Integral Management Approach): Does the Internal and External Cultural Orientation Matter? Acta Polytechnica Hungarica, 9,2744, 2012 